\title{
Permanent Neonatal Diabetes Mellitus
}

National Cancer Institute

\section{Source}

National Cancer Institute. Permanent Neonatal Diabetes Mellitus. NCI Thesaurus. Code C114902.

Hyperglycemia in the first month of life due to a genetically determined defect in the structure, secretion and/or function of insulin that does not resolve spontaneously. 